\title{
A MAIORIDADE FRENTE À SOCIEDADE E ÀS INCLINAÇÕES NATURAIS SEGUNDO KANT
}

\author{
The maturity regarding society and natural inclinations according to Kant
}

Hedgar Lopes Castro*

Resumo: O presente artigo trata da relação existente entre sujeito, determinações sociais e inclinações naturais, com base na questão da maioridade, da autonomia da vontade e do imperativo categórico que Kant apresenta em três de suas obras sobre a ética. O sujeito está dividido entre diversas tendências; aquele que não sai delas e, portanto, não introduz em si mesmo a liberdade de agir e decidir o que fazer, está fadado a viver na minoridade, como um sujeito inautêntico, por assim dizer. Entretanto, ao estabelecer-se como sujeito de liberdade e autonomia, que reconhece a valor do dever por ele mesmo, passa a ser capaz de governar-se a si mesmo, ainda que, para isso, seja necessária a força do imperativo categórico em suas deliberações racionais para viver. O sujeito não deve ser conduzido, nesse sentido, por nada que lhe seja externo, ainda que necessidades naturais e regras sociais devam por ele ser seguidas, uma vez que a vida subjetiva não pode ser totalmente derivada de sua capacidade de pensar e agir. Palavras-chave: Maioridade. Autonomia. Dever. Imperativo Categórico. Sujeito.
Abstract: The present article deals with the existent relation between the subject, social determination and natural inclinations, based on the question of maturity, the autonomy of the will and the categorical imperative that Kant presents in three of his works on the ethics. The subject is divided between several tendencies; that one that does not leave them and, therefore, does not introduce in itself the freedom to act and to decide what to do, is fated to live in the minority, as an inauthentic subject, so to speak. However, when establishing itself as the subject of freedom and autonomy, who recognizes the value of the duty for itself, he starts to be able to govern himself, though, for him, the force of the categorical imperative is necessary in his rational deliberations to live. The subject does not have to be lead, in this sense, by anything that is still external to him, despite natural necessities and social rules must be followed by him, once the subjective life cannot be totally derived from his capacity of thinking and acting.

Keywords: Maturity. Autonomy. Duty. Categorical imperative. Subject.

*Mestrando em Filosofia na Universidade Estadual do Ceará. Contato: hedgarrr@gmail.com

\begin{tabular}{|c|c|l|l|c|c|}
\hline Intuitio & $\begin{array}{c}\text { ISSN } \\
1983-4012\end{array}$ & Porto Alegre & Vol.9- N $^{\circ} .2$ & $\begin{array}{c}\text { Dezembro } \\
2016\end{array}$ & pp. 61-73 \\
\hline
\end{tabular}




\section{Introdução}

Tanto na sociedade atual como na época de Kant é possível visualizar sujeitos éticos em estado de minoridade: são aqueles que não se governam a si mesmos mediante o próprio pensamento e por isso necessitam de diretrizes e normas externas para compreender e realizar as suas ações e decisões. A minoridade é estabelecida e mantida por ditames e limites sociais e naturais, que regem toda a vida do sujeito que não vive sob a lei moral, a qual se origina e se sustenta racionalmente. Ao contrário desse estado, o sujeito, tendo atingido a maioridade, procura não meramente seguir as regras e determinações da sociedade e as inclinações da natureza, do afeto, das motivações particulares e contingentes, mas tornar-se base e centro de si mesmo, de suas ações e decisões, o que já seria o ser humano propriamente moral que Kant constitui.

O trabalho se divide em duas partes, que se sucedem: em primeiro lugar, explicitar-se-á o conceito de esclarecimento em Kant, a partir de sua obra Resposta à pergunta: Que é esclarecimento?, a fim de problematizar a formação de um sujeito regido pela maioridade e não mais pela minoridade moral; em segundo lugar, explicitar-se-á, a partir do cotejo das obras Crítica da razão prática e Fundamentação da metafísica dos costumes, a questão da autonomia como pressuposto para que o sujeito não se conforme com as regras, determinações sociais e inclinações naturais que surgem em oposição à vida e à conduta propriamente morais. Tratar-se-á, portanto, de pensar uma revolução drástica que Kant provocou em termos de moralidade, revolução que atina, sobretudo, para a natureza do sujeito moderno. Nesse sentido, as orientações morais que passam a ser dispostas como imperativos (princípios e mandamentos objetivos) só podem sê-lo se antes forem pensadas a prática interessada (egoísta), que devem ser posteriormente reformuladas e pensadas como puro e racional respeito à lei moral. O objetivo central do trabalho é explicitar a separação da heteronomia em relação à autonomia: aquele que vive mediante a vontade e o dever deve ser submetido à determinação do imperativo categórico, o que explicita uma plena subjetividade, porque baseada na liberdade fundamental do sujeito. A única lei que deve ser seguida é aquela propriamente moral, não aquela que socialmente é estabelecida sem partir desses pressupostos. Todo o trabalho estará destinado a responder duas questões fundamentais: como a autonomia se distingue da heteronomia? E por que a lei moral deve ser um imperativo a todo sujeito?

\section{O desenvolvimento da maioridade conducente à autonomia da vontade}

Kant, a propósito do período histórico e filosófico do iluminismo, projetou o seu pensamento filosófico sobre o sujeito moral, centrando-se nos conceitos de entendimento ${ }^{1}$ e razão prática ${ }^{2}$ como sendo

1 “Como nenhuma representação se refere imediatamente ao objeto, a não ser a intuição, nunca um conceito se referirá imediatamente a um objeto senão a qualquer outra representação desse objeto (seja intuição, seja conceito).

\begin{tabular}{|c|c|c|c|c|c|}
\hline Intuitio & $\begin{array}{c}\text { ISSN } \\
1983-4012\end{array}$ & Porto Alegre & Vol.9- No.2 & $\begin{array}{c}\text { Dezembro } \\
2016\end{array}$ & pp. 61-73 \\
\hline
\end{tabular}


fundamentalmente constituintes e dirigentes de sua vida livre. No entanto, esse quadro da vida humana é oposto ao que em sua época Kant observava: “a preguiça e a covardia são as causas pelas quais uma parte tão grande dos homens, libertos há muito pela natureza de toda tutela alheia (naturaliter majorennes), comprazendo-se em permanecer por toda sua vida menores [...]”3. As inquietações kantianas sobre a moral, pois, aludiam à percepção de que o sujeito precisaria ser consciente, autônomo e, por isso, que deveria constituir-se sabendo que não há determinações naturais como perspectiva de suas ações e decisões. Estaria o sujeito, desse modo, estabelecendo, com base no entendimento e à luz da razão, uma revolução interna, uma revolução tanto psicológica quanto intelectual e, sobretudo, moral. A defesa de tal empreendimento fez que Kant formulasse uma orientação à vida propriamente ética, orientação esta que designaria todos aqueles sujeitos ainda na fase da minoridade a uma superação de sua condição.

A minoridade, para Kant, “[...] é a incapacidade de se servir de seu próprio entendimento sem a tutela de outrem. É a si próprio que se deve atribuir essa minoridade, uma vez que ela não resulta da falta de entendimento, mas da falta de resolução e de coragem necessárias para utilizar seu entendimento sem a tutela de outro"4. Aí se encontra a indicação da existência de seres menores, os quais não vivem segundo seu próprio entendimento em cada uma de suas ações e decisões, visto que dependem do intermédio de normas e fórmulas da sociedade derivantes. Além de haver comodidade no sujeito ao ser assim passivo porque se demite de pensar no que faz e em sua condição dentro da sociedade que habita -, há cada vez mais ofertas ou atrativos a convencê-lo desse estado, que aparenta ser insolúvel para muitos sujeitos. Do lado e além dessa covardia passiva em que se situam, há a submissão às paixões, inclinações e aos impulsos, conhecida por uma espécie de prisão que mantém a alma humana na condição da minoridade, o que se soma à sua condição, já referida, de sujeito condicionado e coagido por inúmeros mecanismos com os quais a sociedade lhe determina.

Segundo Haide Maria,

[...] Kant elabora sua teoria buscando alicerçar as relações sociais através do princípio fundador da sociedade, que ele elege como 'princípio supremo da moralidade'. Para ele este princípio é o cimento da sociedade e está alicerçado em duas máximas: a primeira diz que nós temos que nos comportar de forma que nossa ação possa ser transformada em lei universal que vai guiar o comportamento de todos; a segunda máxima diz que não basta que nossa ação tenha se transformado em uma lei universal, mas, também é

O juízo é, pois, o conhecimento mediado de um objeto, por conseguinte, a representação de uma representação desse objeto” (KANT, Emmanuel. Crítica da razão pura. Tradução Manuela Pinto dos Santos; Alexandre Fradique. 5 ed. Lisboa: Fundação Calouste Gullbenkian, 2011, A 69/B 94).

2 "Para Kant, a razão prática pura apresenta-se como o único e exclusivo fundamento para a moral, nenhum outro é suficientemente capaz de impor, totalmente a priori, à vontade humana uma lei válida objetivamente à conduta de todo ente racional" (SOUZA, Hélio José dos Santos e. O problema da motivação moral em Kant. São Paulo: UNESP, 2009, p. 43-44).

${ }^{3}$ KANT, Imamnuel. Resposta à pergunta: Que é esclarecimento? Tradução: Floriano de Sousa Fernandes. Textos Seletos. 3. ed. Petrópolis, RJ: Editora Vozes, 2005, p. 1.

${ }^{4}$ KANT, Imamnuel. Resposta à pergunta: Que é esclarecimento? Tradução: Floriano de Sousa Fernandes. Textos Seletos. 3. ed. Petrópolis, RJ: Editora Vozes, 2005, p. 1.

\begin{tabular}{|c|c|l|l|c|c|}
\hline Intuitio & $\begin{array}{c}\text { ISSN } \\
1983-4012\end{array}$ & Porto Alegre & Vol.9- No.2 & $\begin{array}{c}\text { Dezembro } \\
2016\end{array}$ & pp. 61-73 \\
\hline
\end{tabular}


necessário que ela seja considerada como uma finalidade em si mesma e não apenas um instrumento da nossa vontade ${ }^{5}$.

A vontade ${ }^{6}$ do sujeito, nesse sentido, deve voltar-se ao estabelecimento de uma sociedade verdadeiramente moral - que se identifique à lei universal que a rege -, e a partir de então cada sujeito deve possuir uma finalidade em si, de modo que sua consciência seja centrada nisso, não em seus interesses particulares. Toda ação está dirigida, portanto, a dois enfoques: a inexistência ou abolição radical do egoísmo, que faria o sujeito agir em vista de um interesse ou uma finalidade meramente interessada e circunstancial; e a razão como a faculdade que possibilitaria a visualização da lei universal que rege a sociedade e cada ação autônoma, a partir de um pensamento racional e não tendencioso às inclinações egoístas.

Tendo em vista que a sociedade assim se caracteriza e que o sujeito moral deve participar, segundo Kant, das relações sociais de modo racional e não egoísta, cabe agora definir com mais propriedade como se dá a passagem da minoridade à maioridade, ou do sujeito menor ao sujeito maior. Em primeiro lugar, devemos esclarecer que o pensamento autônomo e a ação deliberada livremente não é uma excepcionalidade, ou permitidos apenas a uma minoria. Os sujeitos devem servir eles próprios de motor - e a razão, ou a racionalidade, lhes é esse motor - para sair desse estado de letargia apontado por Kant e para fazer uma revolução interior, tendo a liberdade como propulsora e comandante desse empreendimento. Ou seja, o motor é ele mesmo porque é nele que residem todas as condições para a desejável e necessária superação à vida moral em sociedade. No entanto, na observação do comportamento social, das relações sociais, apresenta-se o contrário: uma invasão heteronômica absoluta, a qual Kant entende como impeditiva à capacidade de arbitrar livremente a ação humana, mas que corresponde à situação do sujeito menor.

Isso ocorre porque, segundo Kant, “[...] toda heteronomia do livre-arbítrio não só deixa de fundamentar qualquer obrigação como, também, resulta de todo contrária ao princípio desse livre arbítrio e à moralidade da vontade"7. Kant também explica o que é esse arbítrio e como ele se fundamenta: "O fundamento da determinação do arbítrio (Willkür) é então a representação de um objeto, e constitui a relação da representação com o sujeito, pela qual é determinada a faculdade de desejar para a realização

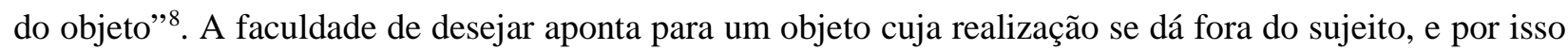

\footnotetext{
${ }^{5}$ HUPFFER, Haide Maria. O Princípio da Autonomia na ética kantiana e sua recepção na obra Direito e Democracia de Jürgen Habermas. In: Revista Anima: Curitiba, v. V, p. 142-163, 2011, pp. 5-6.

${ }^{6}$ Kant define o conceito de vontade relacionando-o à lei universal e à razão: "Tudo na natureza age segundo leis. Só um ser racional tem a capacidade de agir segundo a representação das leis, isto é, segundo princípios, ou: só ele tem uma vontade. Como para derivar as acções das leis é necessária a razão, a vontade não é outra coisa senão razão prática” (KANT, Immanuel. Fundamentação da Metafísica dos Costumes. Tradução: Paulo Quintela. Lisboa: Edições 70, 1986, p. 47).

${ }^{7}$ KANT, Immanuel. Crítica da razão prática. Tradução: Artur Morão. Lisboa: Edições 70, 1989, p. 70.

${ }^{8}$ KANT, Immanuel. Crítica da razão prática. Tradução: Artur Morão. Lisboa: Edições 70, 1989, p. 45.
}

\begin{tabular}{|c|c|c|c|c|c|}
\hline Intuitio & $\begin{array}{c}\text { ISSN } \\
1983-4012\end{array}$ & Porto Alegre & Vol.9- $\mathrm{N}^{\circ} .2$ & $\begin{array}{c}\text { Dezembro } \\
2016\end{array}$ & pp. 61-73 \\
\hline
\end{tabular}


torna-se dependente daquilo que o realiza. Em outras palavras, quando o sujeito se torna maior, ele não se submete à heterogeneidade dos desejos e inclinações, nem das determinações materiais relativas à vida social; a maioridade o permite, ao contrário, conhecer o real significado da liberdade; esta é a sua condição ética por excelência, porque é somente nesse estado que os seres humanos conquistam a capacidade para conhecer a lei moral sem ser condicionado pela sua subjetividade egoísta, que constitui uma prisão que não o permite conhecer e vincular-se à forma da lei racional. Conformar-se a esta lei o condiciona a fazer uso do próprio entendimento, o que demanda um esforço que um número exíguo da população está disposto a despender.

A exiguidade de seres humanos que podem ser considerados como fazendo uso de sua razão para viver e comportar-se moralmente pode ser fundamentada com essa explicação de Ernst Tugendhat:

Existem [...] duas possibilidades distintas de se comportar moralmente frente a um outro, independente das próprias inclinações particulares e apenas porque ele é um ser humano: ou porque eu o devo - 'por dever' - ou por filantropia, quer dizer, por afeição, compaixão, inclinação, que agora contudo seria uma espécie de inclinação universal, também intencionada no cristão 'ama teu próximo, porque ele é como tu' '.

Toda inclinação, sendo um afeto imediato, condiciona o sujeito a não usar ou suspender o uso da razão para determinar a vontade e a obrigação que devem ser o princípio da ação; se a espontaneidade ou a filantropia, ainda que universal, substituíssem-no, certamente a lei universal da razão seria degradada e desrespeitada, por mais que nela contivesse uma inspiração cristã. E, nesse caso, haveria um retorno à condição de minoridade do sujeito; o princípio fundamental da liberdade cessaria, ou pelo menos seria refreado, se o sujeito se acostumasse ou aceitasse que uma força espontânea substituísse sua razão. No entanto, é necessário esclarecer que, segundo Raymond Vancourt, “a doutrina do cristianismo, mesmo ainda antes de ser considerada como doutrina religiosa, apresenta um conceito do soberano bem (do reino de Deus) que é o único que satisfaz as mais rigorosas exigências da razão prática” ${ }^{10}$.

Por outro lado, brada Kant, “uma época não pode se aliar e conspirar para tornar a seguinte incapaz de estender seus conhecimentos [...], de libertar-se de seus erros e finalmente fazer progredir o Esclarecimento. Seria um crime contra a natureza humana, cuja natureza original reside nesse progresso"11. Essas palavras implicam a necessidade de expor outro sentido de maioridade: manter tal vigor de liberdade que esta continue viva e abrangente ainda que um sujeito temporariamente não possa usar o todo de sua razão em vida e em sociedade, lutando para preservar-se, acima de tudo, em sua natureza. É verificável que a sociedade afeta e determina todos os sujeitos, a ponto de serem submetidos a

\footnotetext{
${ }^{9}$ TUGENDHAT, Ernst. Lições sobre ética. Petrópolis: Vozes, 1997, p. 123.

${ }^{10}$ VANCOURT, Raymond, Kant. Lisboa, Edições 70, 1962, p. 100. Foge do enfoque desse artigo tematizar o cristianismo e a moral cristã, mas é importante destacar que ele é uma moral exemplar, porque implica e conduz à santidade do homem.

${ }^{11}$ KANT, Imamnuel. Resposta à pergunta: Que é esclarecimento? Tradução: Floriano de Sousa Fernandes. Textos Seletos. 3. ed. Petrópolis, RJ: Editora Vozes, 2005, p. 5.
}

\begin{tabular}{|c|c|c|c|c|c|}
\hline Intuitio & $\begin{array}{c}\text { ISSN } \\
1983-4012\end{array}$ & Porto Alegre & Vol.9- $\mathrm{N}^{\circ} .2$ & $\begin{array}{c}\text { Dezembro } \\
2016\end{array}$ & pp. 61-73 \\
\hline
\end{tabular}


papéis que a eles são delegados por ela; mas não há nisso nenhuma determinação de que eles deixem de ser plenamente livres ou se manterem perfeitamente esclarecidos, na maioridade. A plenitude da liberdade não se iguala, porém, ao conceito de livre-arbítrio. Kant define o livre-arbítrio do sujeito em contraste com a natureza sensível: “a sensibilidade não torna necessária a sua ação e o homem possui a capacidade de determinar-se por si, independentemente da coação dos impulsos sensíveis"12. E assim Flamarion Tavares complementa esse conceito: “[É] o arbítrio que pode ser determinado pela razão pura, opondo-o àquele determinável pela inclinação (arbitruim brutum) ${ }^{13}$. Ou seja, ainda que os sujeitos sejam submetidos à sensibilidade e aos desejos, os quais não lhes permitem visualizar e atinar para a lei universal e moral, fundada na razão pura, eles podem ser absolutamente livres a cumprir o dever que lhes cabe: estes estão no reino da Liberdade. Segundo Flamarion, “a liberdade é, pois, um conceito que se torna a pedra angular de todo o edifício do sistema kantiano, na medida em que sua realidade é demonstrada por uma lei apodítica da razão prática” ${ }^{14}$. Formalmente, o fim último do ser humano é a liberdade: eis o que o sujeito na maioridade compreende.

Para a superação da minoridade, portanto, é necessária a determinação da razão; porque somente desta maneira o sujeito conseguirá viver sem ser condicionado a tudo que terceiros já deliberaram em seu lugar e sem sua anuência ou participação, dado que são, nesse estado, menores; e isso é necessário acima de tudo para poder exercer dignamente sua participação social, posto que um compromisso patente dele deva ser estabelecido mediante o acordo feito inicialmente por ele mesmo - os deveres e atividades de qualquer cidadão, por exemplo. A maioridade sugere uma linha de ações e uma consciência contrárias à preguiça e a favor da coragem a sair da ignorância, da minoridade de ser determinado sob a desconsideração da liberdade legítima do sujeito maior. Somente sendo maior o sujeito pode entrar no mundo moral, diferenciado do mundo natural onde reinam ocorrências e disposições que não o permitem ser de todo livre. Esse mundo moral se baseia no poder da vontade, que não o constrange como no mundo social e natural é constrangido.

Agora, precisaremos esclarecer o que Kant considera como condição sem a qual a ordem inteligível, ou o mundo moral da liberdade, não pode realmente ser pensado e exercido pelo sujeito, independentemente de suas particulares inclinações e aspirações. Esta condição chama-se vontade. Segundo Kant,

A matéria de um princípio prático é o objeto da vontade. Pois bem: esse objeto é ou não o princípio que determina a vontade. Se fosse o fundamento de determinação da mesma, estaria a regra da vontade submetida a uma condição empírica (a relação da

\footnotetext{
${ }^{12}$ KANT, Emmanuel. Crítica da razão pura. Tradução Manuela Pinto dos Santos; Alexandre Fradique. 5 ed. Lisboa: Fundação Calouste Gullbenkian, 2011, B562)

${ }^{13}$ LEITE, Flamarion Tavares. 10 lições sobre Kant. Petrópolis. RJ: Vozes, 2007, p. 77-78.

${ }^{14}$ LEITE, Flamarion Tavares. 10 lições sobre Kant. Petrópolis. RJ: Vozes, 2007, p. 79.
}

\begin{tabular}{|c|c|l|l|c|c|}
\hline Intuitio & $\begin{array}{c}\text { ISSN } \\
1983-4012\end{array}$ & Porto Alegre & Vol.9- N $^{\circ} .2$ & $\begin{array}{c}\text { Dezembro } \\
2016\end{array}$ & pp. 61-73 \\
\hline
\end{tabular}


representação determinante com o sentimento do prazer ou da dor) e, por conseguinte, não seria uma lei prática ${ }^{15}$.

À diferença da liberdade, a vontade é a razão dirigida à prática por meio da lei moral, assumindo seu papel de julgar os pressupostos e valores que estão implicados em cada ação. Em um horizonte estabelecido moralmente, só podemos agir e decidir com base na vontade.

Como conseqüência do conceito de vontade para a moral, é igualmente importante e necessário falar da autonomia da vontade com base na razão pura, mais conhecida como autodeterminação do sujeito. Ela está ligada à desvinculação completa dos fenômenos empíricos e contingentes; estes não estão e não podem estar comprometidos com a razão, com uma ação e a uma decisão cujos fins são postos sob a determinação da vontade. Seguindo esse raciocínio, Kant explica que "só então a razão, determinando por si mesma a vontade (não estando a serviço das inclinações) é uma verdadeira faculdade superior de desejar, subordinando-se à mesma a faculdade psicológicamente determinável, real e especificamente distinta desta última [...]”16. Com essa explicação podemos claramente perceber que razão e a vontade se conciliam, porque ambas não aceitam a participação ou intrusão, no ato moral, das inclinações e aspirações egoístas do sujeito. E é nesse sentido que Kant, em sua Fundamentação, conclui: "Tudo portanto o que é empírico é, como acrescento ao princípio da moralidade, não só inútil mas também altamente prejudicial à própria pureza dos costumes $[\ldots]^{17}$. Empiricamente, é previsto racionalmente $o$ dever que o sujeito exerce em busca de distinguir o que é digno para ele. Por exemplo: se há leis regentes da sociedade que preconizam e defendem o livre transitar de cada indivíduo em seu cotidiano, elas na verdade dispensam-no de consultar ou viver de acordo com a lei moral. Porque esta lei moral assimila e abarca justamente aquele sujeito que atingiu a maioridade e não mais necessita, por isso, de leis exteriores - sociais - visto que as interiorizou em si mesmo. Aos seres racionais - seres na maioridade -, e somente a eles, dirige-se aquela espécie de lei agora exemplificada, não dadas pela sociedade e cuja finalidade será mais adiante tratada.

A maioridade do sujeito é requisitada porque ele está apto a autodeterminar-se, a reconhecer a autonomia racionalmente; e é capaz, assim, de enxergar todas as ações e seus respectivos fins que a vontade preconiza; tais são fundamentais e irrevogáveis como matéria da lei, pois a autonomia os habita. Essa é a liberdade em um sentido específico: o da autonomia como autodeterminação, que proporciona ao sujeito a determinação não só do seu agir, mas também dos fins de suas ações. E isto dar-se-ia por meio da vontade do sujeito, assim como observando a validade universal que confere à ação humana, posto que as aspirações e inclinações subjetivas jamais podem ser cogitadas à normatização e legislação dela. A lei,

\footnotetext{
${ }^{15}$ KANT, Immanuel. Crítica da razão prática. Tradução: Artur Morão. Lisboa: Edições 70, 1989, p. 56.

${ }^{16}$ KANT, Immanuel. Crítica da razão prática. Tradução: Artur Morão. Lisboa: Edições 70, 1989, p. 52-53.

${ }^{17}$ KANT, Immanuel. Fundamentação da Metafísica dos Costumes. Tradução: Paulo Quintela. Lisboa: Edições 70, 1986, p. 65.
}

\begin{tabular}{|c|c|c|c|c|c|}
\hline Intuitio & $\begin{array}{c}\text { ISSN } \\
1983-4012\end{array}$ & Porto Alegre & Vol.9- $\mathrm{N}^{\circ} .2$ & $\begin{array}{c}\text { Dezembro } \\
2016\end{array}$ & pp. 61-73 \\
\hline
\end{tabular}


particularmente a universal, objetiva sempre à liberdade, oposta e inconciliável à observação de ocasiões fortuitas ou determinações sociais ou políticas; estas somente podem determinar o interesse do indivíduo, tornando-o incapaz de uma consideração intelectual prática verdadeiramente moral, pois negando sua própria autonomia. A supremacia desta é o princípio da moralidade; portanto, não se deve escolher nada a não ser aquilo que esteja de acordo à máxima universal: eis aí aonde se encaixa a proposta da autonomia, porque o sujeito a si se conhece e à vontade, baseada na razão, se submete. Ressaltando que somente o ser humano se vale da vontade, seria inconcebível pretender que a heteronomia das leis motivasse e conduzisse aos princípios e leis que pudessem guiar a conduta humana em vez dela; os objetos externos à razão não podem fornecer as normas da lei que governam o sujeito e assim substitui-la.

As normas sociais necessitam existir, como sabemos todos; no entanto, elas não podem determinar a autonomia de ninguém. Segundo Francisco Javier Herrero, “o ser humano é essencialmente autônomo, não por pertencer a uma determinada comunidade, não por compartilhar com os outros uma determinada tradição, mas por ser sujeito da razão incondicional. É isto que Kant sublinha, é isto que o torna incondicionalmente contemporâneo ${ }^{18}$. O sujeito, além de participar de uma comunidade a qual o envolve e na qual habita, além de determinar-se em sendo autônomo, pode autolegislar, nos desejos e inclinações, sobre aquilo que será bom para si mesmo. Não porque isso seja interessante a ele, mas porque é racionalmente escolhido e determinado. A finalidade do sujeito prático kantiano, portanto, não é jamais egoísta - como em todo sujeito desprovido da força da razão - posto que ele se encontra efetivamente no mundo moral, mundo que está sob a luz da autonomia da vontade e que transcende até mesmo a comunidade que lhe determina circunstancialmente. Entretanto, o que é exatamente essa finalidade e esse mundo que ela rege? Ao que, propriamente, ela tende?

\section{A autonomia como imperativo versus a heteronomia da natureza e da sociedade}

Ao erguer a liberdade ao patamar de condição fundamental de sua ética, Kant precisou, anteriormente, defini-la como sendo a priori. Somente essa definição possibilitaria um mundo, uma vontade e um sujeito verdadeiramente morais. Na presente seção, essa será a questão norteadora: como a liberdade torna-se absoluta para o indivíduo, sem que ele caia novamente na minoridade? Pois não haverá permanência da liberdade e da autonomia se permanece o que no mundo social e natural pode apresentarse como máximas e orientações imorais à conduta do sujeito. Assim, ele precisa constituir e basear-se em outra coisa que o assegure na vida sob a luz da lei moral, acima do seu conhecimento sobre os fenômenos que a todo instante lhe acometem. E a esta coisa dá-se o nome de pensamento.

${ }^{18}$ HERRERO, Francisco Javier. “A Ética de Kant”. In: Revista Síntese, Belo Horizonte, v. 28, n. 90, p. 17-36, 2001, p. 19-20.

\begin{tabular}{|c|c|l|l|c|c|}
\hline Intuitio & $\begin{array}{c}\text { ISSN } \\
1983-4012\end{array}$ & Porto Alegre & Vol.9- N $^{\circ} .2$ & $\begin{array}{c}\text { Dezembro } \\
2016\end{array}$ & pp. 61-73 \\
\hline
\end{tabular}


Segundo Herrero, “o nosso conhecimento não pode ultrapassar os limites da possível experiência, ele se refere só aos fenômenos. A coisa em si é incognoscível. [...] Se o nosso conhecimento fica limitado, abre-se em compensação o âmbito da razão pura prática, no qual a liberdade pode ser pensada"19. O pensamento é a atividade intelectual que acessa o mundo em si, o mundo não dos fenômenos, mas numênico, o mundo próprio à liberdade. Existe então um mundo numenal no qual a maioridade moral ingressa; um sujeito maior se assenta perfeitamente nele. Não se trata, nesse sentido, de uma mera evolução da minoridade: trata-se de uma nova forma de vida, mais legitimamente humana e mais digna, pois regida pelos princípios e potencialidades que Kant julga propriamente humanos. A consciência do sujeito passa a ser literalmente revolucionada, pois não mais enxerga o que lhe é exterior como princípio ou motor de sua vontade e ação, as quais passam a ser orientadas de acordo com a sua própria razão: $a$ priori. É justamente isso ao que atenta Maria Margareth, ao expor como Kant separa o mundo supremo da moralidade do mundo comum e da pura experiência:

[...] Kant propõe fixar um princípio supremo da moralidade, elaborando uma filosofia moral que seja depurada de tudo que seja empírico. Assim, Kant questiona a natureza da ciência, pois entende que devemos separar a parte empírica da parte racional. Tal proposta de separação se dá em função do que o filósofo considera fundamental, ou seja, elaborar uma filosofia moral que não tenha como fundamento nada que seja obtido da experiência” 20 .

O respeito, desse ponto de vista, é o esforço próprio do sujeito moral, no sentido de torná-lo cada vez mais racional e livre, nunca submisso aos ditames exteriores, empíricos - a saber, sociais e naturais encontrados na experiência da vida comum, que de modo algum estão comprometidos com a razão pura. Ademais, os sentimentos são diferentes das inclinações. As inclinações são sempre materiais e $a$ posteriori estabelecidas, jamais formais e a priori; os sentimentos, diferentemente, nem sempre se encaixam nas inclinações, todavia. Para Kant, até mesmo o prazer pode ser apresentado como sentimento propriamente moral, no seguinte sentido: “[...] o que determina imediatamente a vontade é, mediante a razão, o sentimento de prazer, sendo aquela determinação, portanto, uma determinação pura prática, e não estética, da faculdade de desejar" 21 . Se o respeito é um sentimento que Kant trata positivamente como sendo a finalidade verdadeira de toda a cultura moral, em radical oposição ao gozo e ao prazer fugazes e mediados pela faculdade de desejar, então o respeito é um imperativo absoluto que se impõe a nós, sujeitos, sem que se mantenha ao sabor de impulsos e tendências baseados tão somente na experiência sensível, que se verificam no sujeito menor.

${ }^{19}$ HERRERO, Francisco Javier. “A Ética de Kant”. In: Revista Síntese, Belo Horizonte, v. 28, n. 90, p. 17-36, 2001, p. 21.

${ }^{20}$ STADNICK, Maria Margareth. O sentimento de respeito na moral kantiana. 2007. Dissertação (Mestrado em Filosofia) - Universidade Federal de Santa Catarina, p. 11.

${ }^{21}$ KANT, Immanuel. Crítica da razão prática. Tradução: Artur Morão. Lisboa: Edições 70, 1989, p. 233.

\begin{tabular}{|c|c|l|l|c|c|}
\hline Intuitio & $\begin{array}{c}\text { ISSN } \\
1983-4012\end{array}$ & Porto Alegre & Vol.9- N $^{\circ} .2$ & $\begin{array}{c}\text { Dezembro } \\
2016\end{array}$ & pp. 61-73 \\
\hline
\end{tabular}


Kant expõe em resumo a estrita relação entre respeito e intelecto: “[...] O respeito para com a lei moral é um sentimento que se produz por um fundamento intelectual, sendo esse sentimento o único que nos é dado conhecer anteriormente a priori e cuja necessidade podemos ter como evidente" ${ }^{22}$. Com isso, constatamos que o respeito é aquilo que assegura que ao campo moral o sujeito esteja vinculado necessariamente, já então completamente isento das opiniões, diretrizes e receitas sociais, tanto como das tendências e inclinações naturais. Se o pensamento racional lhe assegura a descoberta e o desbravamento do mundo com base no dever ${ }^{23}$, certamente o que é necessário se impõe em sua vida, e reconhecemos nisso um sentimento de respeito que o sujeito estabelece consigo mesmo. Entretanto, Kant adverte: "Mas daqui não se pode concluir com segurança que não tenha sido um impulso secreto do amor-próprio, oculto sob a simples capa daquela ideia, a verdadeira causa determinante da vontade”24. Assim, a jornada, por assim dizer, de todo homem que concretiza a liberdade na vida prática, agindo com base na vontade racional, é caracterizada por um relacionamento necessário e inalienável com a lei que o governa autonomamente; e não haverá espaço para amor-próprio, uma vez que nos impele unicamente o cumprimento do dever e a realização do respeito moral.

Antes desse estado, no entanto, é evidente que há percalços aos quais se depara aquele que se firma em concretizar a autonomia da vontade em si mesma e o respeito puro à lei moral. Os percalços, porém, o sujeito deve confrontar e derrotar, pois é fundamental que não atrapalhem a mais digna das empreitadas, a saber, o exercício da moralidade. Kant, nesse sentido, revela-se irresoluto no que tange à sua concepção de agir segundo o princípio, ou seja, segundo o dever no qual jamais interfere um sentimento ou um impulso que não o do respeito, que nos permite uma vida inteiramente racional com os nossos semelhantes ${ }^{25}$. Portanto, quanto mais forem combatidas e afastadas as coisas irracionais que são residentes no homem, tanto mais haverá capacidade dele ao pleno exercício já referido. Caso exista algum titubeio frente a isso, ele regredirá: a sua vontade e liberdade serão vencidas, o que aponta à determinação não-moral do sensível à sua conduta, tal como acontece quando há interesse próprio ou fins sociais estabelecidos convenientemente a servir de motor ao seu agir, um agir que, por isso mesmo, torna-se impossível ser moralmente verdadeiro e válido.

\footnotetext{
${ }^{22}$ KANT, Immanuel. Crítica da razão prática. Tradução: Artur Morão. Lisboa: Edições 70, 1989, pp. 150-151.

23 "Kant explica o conceito de dever no seguinte trecho, a partir da razão e relacionando-o diretamente com o respeito e com a vontade, que deve ser boa em si mesma: "Ora, a razão exige-me respeito por uma tal legislação, da qual em verdade presentemente não vejo em que se funde [...], mas de que pelo menos compreendo que é uma apreciação do valor que de longe ultrapassa o de tudo aquilo que a inclinação louva, e que a necessidade das minhas acções por puro respeito à lei prática é o que constitui o dever, perante o qual tem de ceder qualquer outro motivo, porque ele é a condição de uma vontade boa em si, cujo valor é superior a tudo” (KANT, Immanuel. Fundamentação da Metafísica dos Costumes. Tradução: Paulo Quintela. Lisboa: Edições 70, 1986, p. 35).

${ }^{24}$ KANT, Immanuel. Fundamentação da Metafísica dos Costumes. Tradução: Paulo Quintela. Lisboa: Edições 70, 1986, p. 40.

${ }^{25}$ KANT, Immanuel. Fundamentação da Metafísica dos Costumes. Tradução: Paulo Quintela. Lisboa: Edições 70, 1986, p. 77.
}

\begin{tabular}{|c|c|c|c|c|c|}
\hline Intuitio & $\begin{array}{c}\text { ISSN } \\
1983-4012\end{array}$ & Porto Alegre & Vol.9- $\mathrm{N}^{\circ} .2$ & $\begin{array}{c}\text { Dezembro } \\
2016\end{array}$ & pp. 61-73 \\
\hline
\end{tabular}


Além de saber que a determinação da ação humana com base em circunstâncias convenientes não conduz a uma vontade que parte de si mesmo, tanto como o reconhecimento do dever aí implícito, precisamos ainda esclarecer o papel do imperativo categórico na moral do sujeito maior, um imperativo que é a fundamentação formal do que sempre e somente deve ser feito. Para Kant, "o imperativo categórico seria aquele que nos representasse uma acção como objectivamente necessária por si mesma, sem relação com qualquer outra finalidade” ${ }^{26}$. Ele define, então, que a ação é necessária por si mesma e não se acha sob submissão de nenhuma espécie; é uma exigência racional e pressupõe validade a todos que sejam realmente humanos, isto é, morais. Kant, desse modo, propõe que ajamos segundo uma máxima, o imperativo categórico, de modo tal que queiramos que nossa ação se torne lei universal; o que estabeleceria à máxima a condição de ser a priori uma regra formal que implica e sustenta a moral ${ }^{27}$. Ou seja, o que é pensado a priori como sendo um imperativo categórico deve ser compreendido como uma reflexão louvável o suficiente a que todos possam agir moralmente.

Faz-se necessário esclarecer que, nas palavras de Raymond Vancourt, “o respeito, sentimento sui generis que se apresenta a Kant como um 'produto espontâneo da razão em nós', desempenha assim o papel de móbil da vida moral: agir moralmente é agir sob o impulso do sentimento de respeito que a lei nos inspira”28. Nesse caso, a lei e o dever serão observados com vigor racional, não sob os influxos de leis sociais e naturais: o imperativo é fundado a fim de preencher uma lacuna que existe no sujeito que ainda não é completamente moral. Ao contrário desse estado tendencioso e imperfeito, o dever tornar-se-á uma lei universal da razão, uma vez que seja ele é uma máxima norteadora da ação, um dever, mas sem imposição externa; à realização de tal efeito deve atentar os imperativos categóricos, mostrando-se objetivos e universais. Só realiza isso quem saiu de todo da minoridade: um sujeito maior, um sujeito que realiza os imperativos categóricos; e, segundo Vancourt, “[...] eles não impõem um acto já logicamente pressuposto num querer anterior; eles não ligam a vontade à matéria do acto, mas à própria acção que ela deve levar a cabo e que não tem, de direito, a possibilidade de não levar a cabo”29.

O sujeito que se funda no imperativo hipotético, porém, e que se define por uma ação interessada e exterior ao dever, não introduz o dever como lei moral, nada mais sendo do que um sujeito que se baseia no próprio egoísmo para viver. Acerca da ordenação e representação interna dos hipotéticos, hipotéticos e categóricos, Kant explica:

[...] Todos os imperativos ordenam ou hipotética ou categoricamente. Os hipotéticos representam a necessidade prática de uma acção possível como meio de alcançar qualquer outra coisa que se quer (ou que é possível que se queira). O imperativo

\footnotetext{
${ }^{26}$ KANT, Immanuel. Fundamentação da Metafísica dos Costumes. Tradução: Paulo Quintela. Lisboa: Edições 70, 1986, p. 50.

${ }^{27}$ KANT, Immanuel. Fundamentação da Metafísica dos Costumes. Tradução: Paulo Quintela. Lisboa: Edições 70, 1986, p. 59.

${ }^{28}$ VANCOURT, Raymond, Kant. Lisboa, Edições 70, 1962, p. 34.

${ }^{29}$ VANCOURT, Raymond, Kant. Lisboa, Edições 70, 1962, p. 35.
}

\begin{tabular}{|c|c|c|c|c|c|}
\hline Intuitio & $\begin{array}{c}\text { ISSN } \\
1983-4012\end{array}$ & Porto Alegre & Vol.9- $\mathrm{N}^{\circ} .2$ & $\begin{array}{c}\text { Dezembro } \\
2016\end{array}$ & pp. 61-73 \\
\hline
\end{tabular}


categórico seria aquele que nos reapresentasse uma ação como objectivamente necessária por si mesma, sem relação com qualquer outra finalidade ${ }^{30}$.

A determinação do imperativo categórico, diferentemente, dá a sustentação racional a que condutas se encaminhem no sentido do que é moral e do que pode, assim, ser praticado por todos os sujeitos morais. O horizonte e o resultado são outros: o imperativo hipotético faz que o sujeito menor limite-se a viver nos moldes das conveniências sociais e tendências naturais, sob as determinações e necessidades por elas ditadas; o imperativo categórico, no entanto, produz no sujeito o olhar inabalável e irredutível para o dever em si, promovendo nele total e radical independência daquelas determinações e necessidades, visto que jamais estará à mercê de desejos e interesses que não são, na verdade, provenientes dele mesmo. O imperativo categórico, por um lado, sendo uma superação do hipotético, significa a desvinculação completa de circunstâncias oportunas, inclinações e objetivos pessoais quaisquer que possam apresentar-se na vida comum do sujeito menor; por outro lado, sob a consideração permanente racional da vida moral, cuja liberdade é o seu princípio fundamental, torna-se uma exigência para a autonomia aos apetites do corpo. Nessa linha, é necessário fidelidade à deliberação da vontade e respeito à lei moral em geral.

\section{Conclusão}

Ficou esclarecido que a heteronomia é própria do sujeito na minoridade; ele não é capaz de determinar leis e máximas do próprio agir, o que o deixa à mercê de inclinações naturais e normas, conveniências sociais de toda espécie. Quando o sujeito se determina não mais como ser heterônomo, a sociedade e a natureza não mais se postam como forças externas que lhe determinam, posto que, nesse estado, ele possui deveres e uma vontade livre de tais exterioridades. Na heteronomia, o sujeito só respeita e obedece a leis externas que pouco ou nada conhece; na autonomia, ao contrário, o sujeito é tão capaz de conhecer o próprio dever que se emancipa. A razão é o mecanismo pelo qual Kant preconiza o pensamento moral excelente, porque respeita e atina para tudo aquilo que é próprio do sujeito moral: para observar em si mesmo a lei à qual se sujeita. Assim, atingir a autonomia da vontade - a lei à qual o sujeito se submete - não é um processo de mediação por ele: a submissão é o respeito à lei, um processo imediato e sustentado, para quem não é sujeito perfeitamente moral, pelo imperativo categórico. Este deve ser igualmente absoluto, porque todo sujeito está fadado a ser vítima de inclinações naturais e determinações sociais que podem agradá-lo ou coagi-lo, e em função das quais agirá; isso sustenta o sujeito que é movido por imperativos hipotéticos, cujo dever é passageiro e moldado sob o interesse de cada um. A lei moral, se

${ }^{30}$ KANT, Immanuel. Fundamentação da Metafísica dos Costumes. Tradução: Paulo Quintela. Lisboa: Edições 70, 1986, p. 50.

\begin{tabular}{|c|c|l|l|c|c|}
\hline Intuitio & $\begin{array}{c}\text { ISSN } \\
1983-4012\end{array}$ & Porto Alegre & Vol.9- N $^{\circ} .2$ & $\begin{array}{c}\text { Dezembro } \\
2016\end{array}$ & pp. 61-73 \\
\hline
\end{tabular}


não for a priori, pelo respeito ao dever, cumprida, tende a consolidar sujeitos que na sociedade não passarão de escravos de leis submetidas à transição, ao jogo de conveniências. O imperativo hipotético, nesse sentido, só serve para contribuir com esse destino; é por isso que se faz necessário que o imperativo categórico tome as rédeas da vida moral do sujeito e o torne senhor de si mesmo, evitando escravizar-se às inclinações naturais e determinações sociais.

\section{Referências}

KANT, Immanuel. Fundamentação da Metafísica dos Costumes. Tradução: Paulo Quintela. Lisboa: Edições 70, 1986.

. Crítica da razão pura. Tradução Manuela Pinto dos Santos; Alexandre Fradique. 5 ed. Lisboa: Fundação Calouste Gullbenkian, 2011.

. Crítica da razão prática. Tradução: Artur Morão. Lisboa: Edições 70, 1989.

. Resposta à pergunta: Que é esclarecimento? Tradução: Floriano de Sousa Fernandes. Textos

Seletos. 3. ed. Petrópolis, RJ: Editora Vozes, 2005.

TUGENDHAT, Ernst. Lições sobre ética. Petrópolis: Vozes, 1997.

VANCOURT, Raymond. Kant. Lisboa, Edições 70, 1962.

LEITE, Flamarion Tavares. 10 lições sobre Kant. Petrópolis. RJ: Vozes, 2007.

HERRERO, Francisco Javier. “A Ética de Kant”. In: Revista Síntese, Belo Horizonte, v. 28, n. 90, p. 1736, 2001. Disponível em: http://faje.edu.br/periodicos2/index.php/Sintese/article/viewFile/563/987. Acessado em: 11/05/2016.

HUPFFER, Haide Maria. O princípio da autonomia na ética kantiana e sua recepção na obra direito e democracia de Jürgen Habermas. In: Revista Anima: Curitiba, v. V, p. 142-163, 2011. Disponível em: www.anima-opet.com.br/pdf/anima5-Seleta-Externa/Haide-Maria-Hupffer.pdf. Acessado em 12/05/2016.

STADNICK, Maria Margareth. O sentimento de respeito na moral kantiana. 2007. Dissertação (Mestrado em Filosofia) - Universidade Federal de Santa Catarina. 118f.

Recebido em: 17 de maio de 2016.

Aprovado para a publicação em: 4 de novembro de 2016.

\begin{tabular}{|c|c|l|l|c|c|}
\hline Intuitio & $\begin{array}{c}\text { ISSN } \\
1983-4012\end{array}$ & Porto Alegre & Vol.9- N $^{\circ} .2$ & $\begin{array}{c}\text { Dezembro } \\
2016\end{array}$ & pp. 61-73 \\
\hline
\end{tabular}

